Dr Mogen Schou in chapters 10 and 14. Dr Scholl of course, has done much to promote this treatment by his patient adrocacy of the real and unique clinical benefits of lithium therapy in the affective disorders. I particularly liked Dr Schou's suggestions that clinicians should record dosage in millimoles lithium, and that drug suppliers should indicate the lithium content of their preparations in the same units. His plea that research reports should state the timing of blood taken for lithium analysis in relation to the last oral dosage of lithium salt is also worthy of mention.

As a clinical chemist I would have wanted some extension of the remarks in chapter 14, page 292 on the need for proper control of serum lithium analysis-and in this context cannot resist asking for more details of the method which allows Drs Gershon and Shopsin in chapter 7 , page 133 to quote serum lithium concentrations to three decimal places. (This in no way detracts from a useful account of lithium toxicity.)

The opening and closing chapters of the book, by Drs N. S. Kline and R. R. Fieve are especially stimulating and outspoken. I was interested, for example, to be reminded by Dr Kline that lithium has a real historical claim to be among the first of the "psychic cnergiscrs" and to read that the very cheapness and availability of lithium salts has made drug houses reluctant to market preparations which may compete with other more complex (and profitable) drugs.

In due course it can be expected that lithium will be superseded by more effective and less toxic substances once the basis of its action on mood is clearly understood. Until that rather distant time comes this volume will be required reading for all of those who wish to improve the treatment of patients suffering severe mood disturbance, by the use of well controlled lithium therapy.

G. S. FELL

\section{Runaway chromosomes}

Chromosomes in Human Cancer. By J. Cervenka and $\mathrm{I}_{\text {. }}$ Koulischer. Pp. viii + 203. (Thomas: Springfield, Ill., July 1973.) $\$ 13.75$.

THE stated purpose of this book is to "gather all available information on chromosomes in human tumours with the fervent hope that they might bo used as a source of understanding of the seemingly disordered chromosomal constitution in human cancer cells and of the few rules which may be derived from these data". The authors have definitely succeeded in the sisyphean task of gathering the information. The book will be a precious source for the quick identification of sources. Is it pre- sumptuous for one who has no clinical qualification to suggest that the fervent hope has not been fulfilled?

The few rules which emerge are commonplaces of the dynamics of cell populations, and indeed of populations in general. These rules derive from first principles of evolutionary genetics (including cytogenetics) and have been experimentally confirmed with unicellular organisms and with cultured somatic cells and transplants of higher organisms including man.

The value of this book does not lie in illuminating the chromosomal mess in tumours. (Incidentally, is enough known about chromosomal variation in normal somatic tissues, especially embryonic?) It lies in the many tablesat least one for each of the major forms of human cancer-which summarises very clearly the published cases in which chromosomal analysis was performed. For this service those engaged in research on tumours, both clinical and experimental, should be grateful to the authors.

\section{G. Pontecon'o}

\section{Life is inorganic too}

Inorganic Biochemistry. Edited by Gunther L. Eichorn. Vol. 1 pp. xxiv + 1-608; vol. 2 pp. xi $609-1263$, (Elsevier: Amsterdam, London and New York, 1973.) Dfl. 300; $\$ 105.30$.

These two volumes do not form a book. Rather they hold together thirty-four booklets running from the necessary inorganic chemistry for the understanding of biological roles of metal ions to the description of the metal-containing biological systems themselves. All the important roles of metals are described but most of the booklets are written by an authority largely for other authorities and in a style which precludes a general reader from getting past the first few pages. Many of the chapters are not therefore readable at a sitting and they could as well have appeared in a review journal where the objective is extensive reference rather than intelligent discussion. In fact it is frequently the case that the biological significance of the materials under discussion is lost among the mass of detail on absorption spectra, FPR signals and Mössbauer data. Striking exceptions are the chapters of Niclands on ion carriers, and by Spiro on phosphate transfer.

I feel that the title of this book should have been 'The Properties of Inorganic Materials found in Biological Systems' for the stress is too far from biological function. The question then arises: is this a book on inorganic biochemistry?

For many years most scientists have looked upon living systems as a growing and self-reproducing organic matrix.

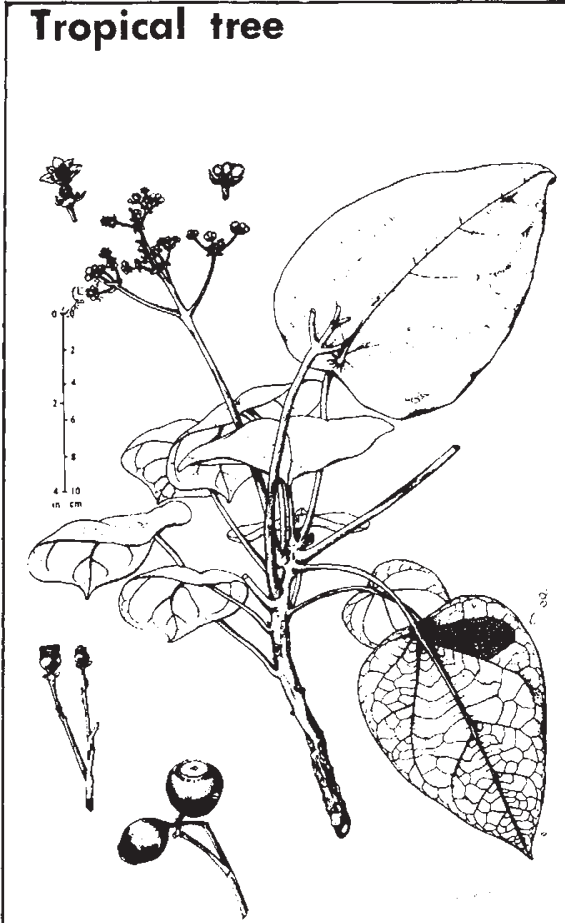

LAEAvs, fruit and flowers of Hernandia nymphreifolin, so called because of the similarity of its leaves to thoss of the watcr lily Nymphaere. This small tree grows on sea coasts in East Africa, southern Asia and the south Pacific. From Tree Flora of Malayn vol. 2, edited by T. C. Whitman for the Forest, Department of Malaysia. (Tongman: Essex, July 1973.) $£ 12.50$

Such a view is a natural development from the separation of the animal and vegetable from the mineral kingdoms. The distinction, perpetuated in the educational divisions of inorganic and organic chemistry has forced inorganic chemistry more and more toward physical sciences and organic chemistry toward life sciences. Today one knows that this distinction, seen in almost every chemistry journal and in most chemistry courses in schools and universities is wrong-headed. Life has evolved from inorganic materials (generating organic chemistry as it went) and in that evolution has incorporated every facet of inorganic chemistry which was profitable to it. This book clearly proves this point. The only reason for using a title such as Inorganic Biochemistry is to get away from the implied title 'Organic Biochemistry' every time an inorganic chemist, reads 'Biochemistry' In other words Avis quite rightly wants a share of Hertz's business: car renting, and the study of biology by chemists, is not a monopoly activity. What then is the inorganic part of hiology?

The roles of inorganic materials can readily be separated into the functions of bulk structural units, such as shells and bones, control elements, such as energy stores in concentration gradients, and catalyst centres. What feel does this 